\title{
CFD SIMULATION OF PRESSURE DROP IN TURBULENCE FLOW OF WATER THROUGH CIRCULAR, SQUARE, RECTANGULAR AND TRIANGULAR CROSS-SECTIONAL DUCTS
}

UDC:532.517.4

Original scientific paper

https://doi.org/10.18485/aeletters.2021.6.1.5

\author{
Melkamu Embiale ${ }^{1}$, Addisu Bekele $^{1^{*}}$, Chandraprabu Venkatachalam $^{1}$, Mohanram Parthiban $^{1}$ \\ ${ }^{1}$ Department of Mechanical Engineering, Adama Science and Technology University, Adama, Ethiopia
}

\begin{abstract}
:
In this paper, the velocity and pressure drop distribution in flowing water through circular, square, rectangular with aspect ratio of 2:1 and $4: 1$ as well as an equilateral triangle cross-sectional ducts with the same duct length and hydraulic diameter have been numerically studied using ANSYS FLUENT tools. The boundary conditions used for the simulation are: at the entrance a velocity inlet of $0.2 \mathrm{~m} / \mathrm{s}$ at $25{ }^{\circ} \mathrm{C}$ constant temperature, at exit a pressure outlet with zero gage pressure and a non-slip is used for the duct walls condition. A steady state and kepsilon turbulence flow model is used. The results have shown that velocity in the ducts gradually increases from zero at the walls to the maximum at the center. In the circular duct $20.327 \%, 15.273 \%, 13.5 \%$ and $6.834 \%$ more pressure is lost than in triangular, square, rectangular aspect ratio of 2:1 and rectangular aspect ratio of 4:1 ducts respectively. In turn, circular duct requires the highest pumping power while triangular one needs the lowest.
\end{abstract}

ARTICLE HISTORY

\section{INTRODUCTION}

Computational Fluid Dynamics (CFD) is the combination of physics, flow technology, computer applications, mathematics and mechanics. It is a group of techniques aimed at solving the Navier Stokes equations, thereby satisfying the conservation of mass, momentum and energy to predict the behavior of fluidic systems. It is used when a high number of design variations are to be analyzed or where physical testing may be prohibited due to restricting factors, such as scale, cost, accessibility, or the presence of physical or environmental hazards [14].
Computational fluid dynamics is widely used to solve complex problems in different fields. Of which the mechanical engineering is a forehead discipline that uses CFD in the areas of [5-7]:

$\checkmark$ Aerodynamics of aircraft

$\checkmark$ Heating ventilation and air conditioning

$\checkmark$ Heat exchangers

$\checkmark$ Flows of fluids through ducts

$\checkmark$ Automotive and etc.

One of the most commonly used industrial equipment is heat exchangers. To improve the efficiency of heat exchangers many attempts have been made by various researchers [8-11]. Larger heat transfer area per volume, greater heat transfer 
coefficient and lower friction factor are always the interest and focus of researchers in choosing the duct geometry of heat exchangers [10]. One of the design techniques used to have efficient and compact or smaller size heat exchangers is obtaining large surface area per volume and decreasing the pressure drop. This can be achieved by changing the circular tubes by polygonal ones [12-16].

Due to the possible existence of static section near the sharp corners of non-circular ducts, the corresponding contact area between the fluid and heat exchanger walls is less when compared to the circular tubes [17].

As a result, heat transfer rate is low because sharp cornered ducts reduce the effective heat transfer surface

In this paper flows of fluid through ducts (specifically water flow) which is used in industries as well as Households will be analyzed for different cross-section ducts with the same hydraulic diameter [18-20]. Hydraulic diameter, by which non circular ducts are treated as circular one, to estimate pressure drop and fluid flow rate calculations is given by the following formula [2].

$$
D_{h}=4 A / P
$$

Where:

$\mathrm{D}_{\mathrm{h}}$ - Hhydraulic diameter,

A - Duct cross sectional area,

$\mathrm{P}-$ Wetted perimeter.

By using this correlation the following different geometries are represented by similar hydraulic diameter.

Aspect Ratio: It is a ratio of two sides of rectangular duct shape (Fig. 1).

Aspect ratio $=a / b$ (Where $a=$ width, $b=$ height) $[3$, 18].

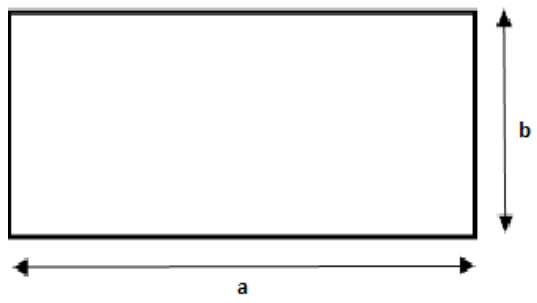

Fig 1. Rectangular duct

\section{PROBLEM SPECIFICATIONS}

As Fig. 2 shows, there are five different crosssectional ducts with similar hydraulic diameter and length. Here, problem specifications and boundary conditions of those ducts and water flow in it would be set, to model and simulate using ANSYS FLUENT (15.0) tool. The lengths and hydraulic diameters of all cross-sectional ducts are set $2 \mathrm{~m}$ and $40 \mathrm{~mm}$ respectively. And the length of each side of the ducts can be calculated from hydraulic diameter by using equation (1) and provided in Table1.

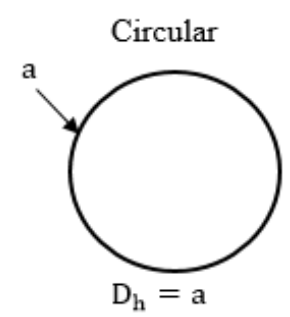

Square

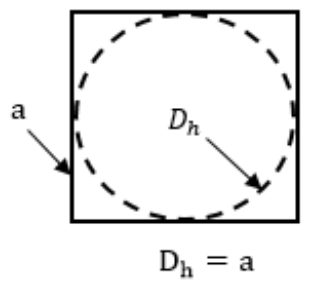

Equilateral triangle
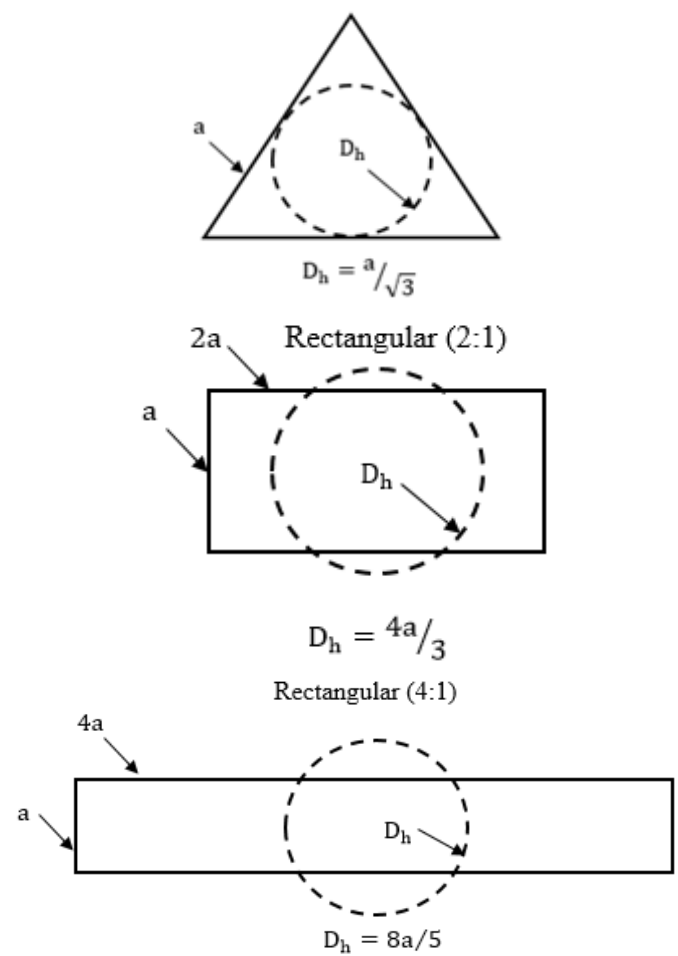

Fig. 2. Five different cross-sectional area ducts with the same hydraulic diameter 
Table 1. The length of each side of the ducts

\begin{tabular}{|l|l|}
\hline Duct cross-sections & Length $(\mathrm{mm})$ \\
\hline Circular & 40 \\
\hline Square & $40 \times 40$ \\
\hline Rectangular with 2:1 aspect ratio & $30 \times 60$ \\
\hline Rectangular with 4:1 aspect ratio & $25 \times 100$ \\
\hline Equilateral Triangular & 69.282 \\
\hline
\end{tabular}

The flowing water goes through straight ducts entering the pipes as velocity and exiting as pressure outlet with zero gage pressure. Boundary conditions and some essential fluid properties are listed in the Table 2.

Table 2. Boundary conditions

\begin{tabular}{|l|c|}
\hline Fluid & Water \\
\hline Constant velocity & $0.2 \mathrm{~m} / \mathrm{s}$ \\
\hline Constant density & $998.2 \mathrm{~kg} / \mathrm{m}^{3}$ \\
\hline Dynamic viscosity & $0.001003 \mathrm{~kg} / \mathrm{ms}$ \\
\hline Time analysis & Steady state \\
\hline Pressure & $\begin{array}{c}\text { Atmospheric } \\
\text { pressure }\end{array}$ \\
\hline Constant temperature & $25^{\circ} \mathrm{C}$ \\
\hline Wall & No-slip condition \\
\hline Turbulence model & k-Epsilon \\
\hline
\end{tabular}

\section{RESULTS AND DISCUSSIONS}

The velocity and total pressure distributions of different cross- sectional ducts with the same hydraulic diameter in straight ducts are illustrated using computational fluid dynamics (CFD) in the Fig.3.

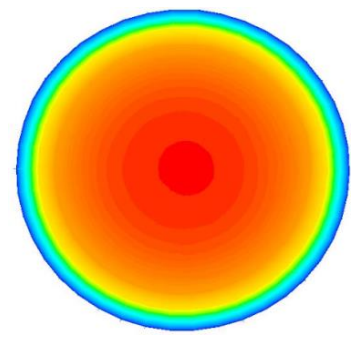

a) Circular

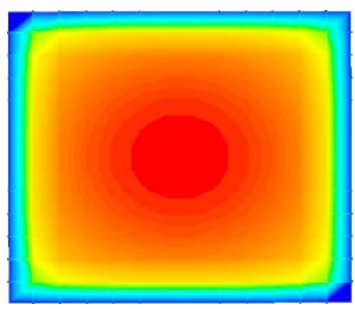

b) Square

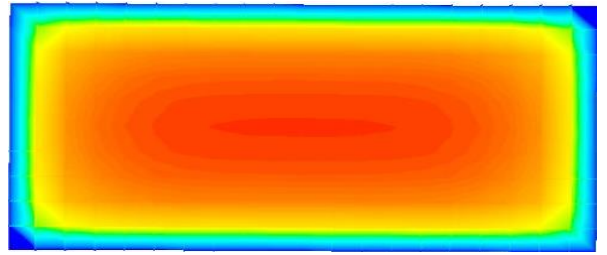

c) Rectangular (2:1)

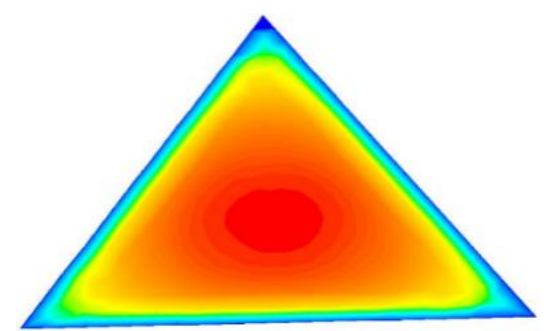

d) Triangular

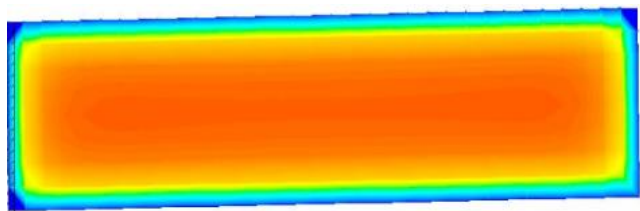

e) Rectangular (4:1)

Fig 3. Velocity contours of circular, square, rectangular and triangular cross-sectional ducts

In Fig.3, Velocity contours in different crosssectional ducts are shown for water fluid. The color range from blue to red shows the velocity range from the minimum to the maximum in the ducts. At the walls the velocity is zero due to no-slip condition, but gradually it increases from zero at the walls to the maximum at the center. In addition, for non-circular ducts the velocity is minimum at the corners because in the vicinity of duct corners there is static section (stagnation) of water.

At sharper corners there is high amount of friction between water flow and corner walls due to high resistance offered by the contact surface on the flowing water. As shown above, the static section is more in triangular duct since it has sharper corners than both square and rectangular ducts.

Similarly the contour plot for pressure distribution in each duct is shown in the Fig. 4 and the total pressure drop in each channel is provided graphically as shown in Fig. 5 and numerically as Table 3. 


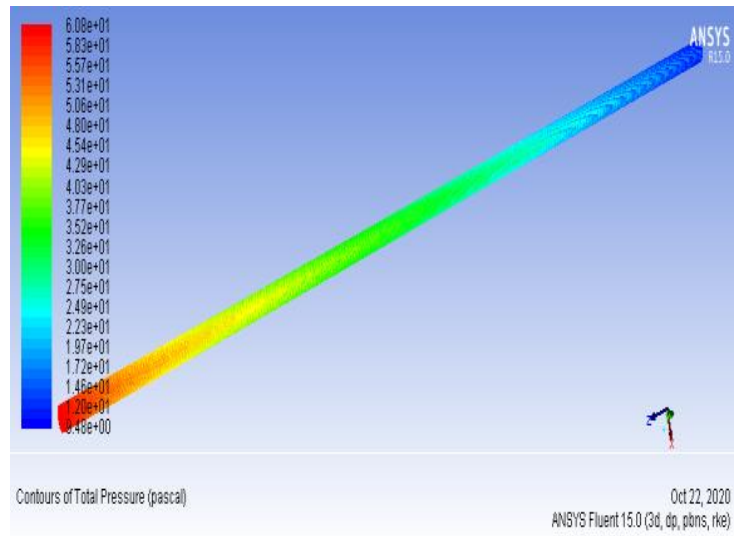

a) Circular duct

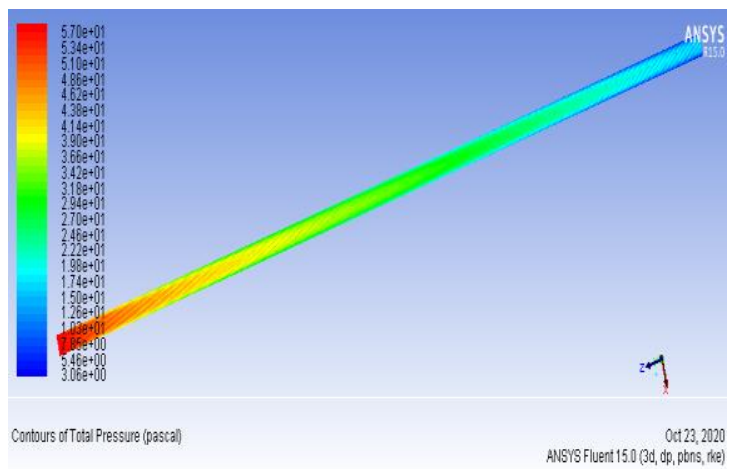

b) Square duct

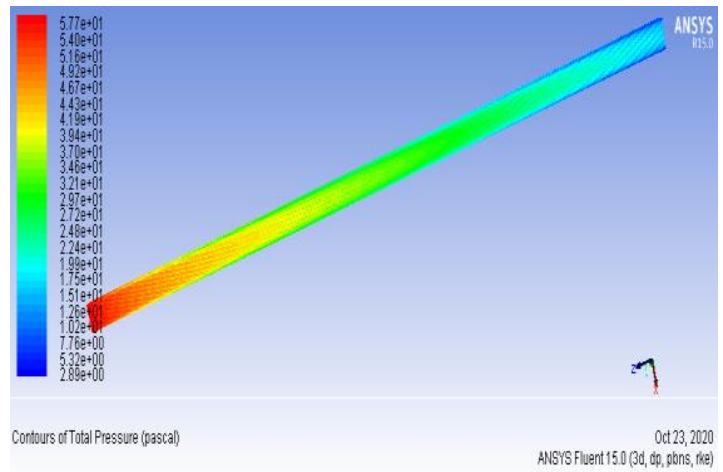

c) Rectangular duct with aspect ratio of 2:1

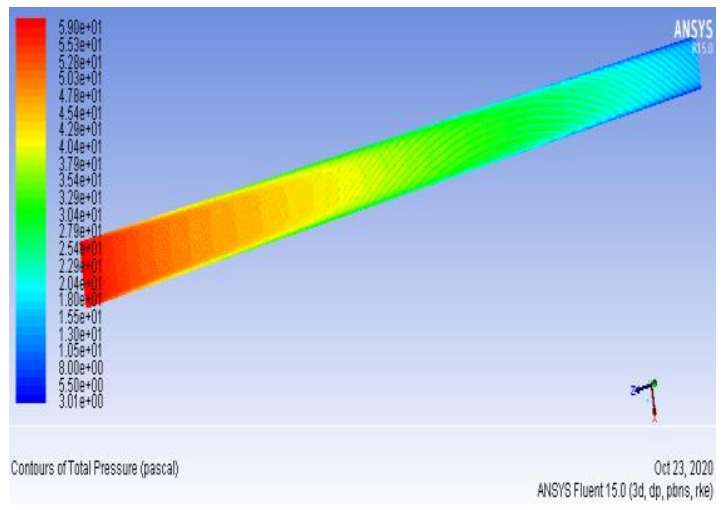

d) Rectangular duct with aspect ratio of 4:1

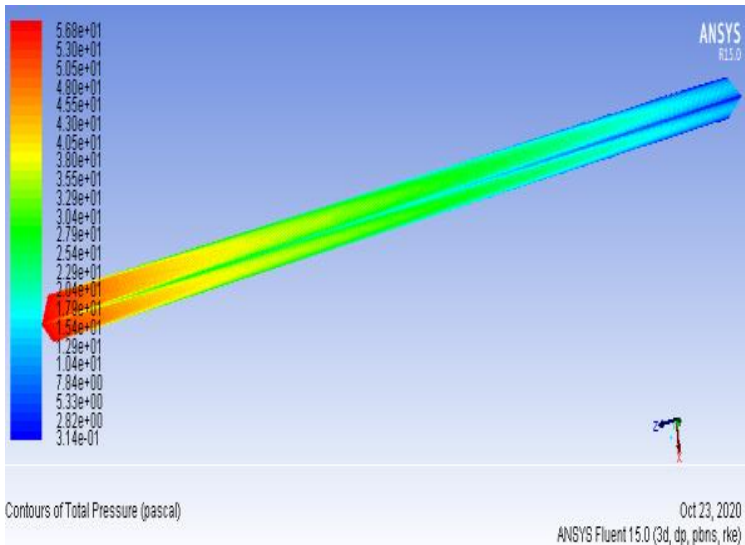

e) Triangular duct

Fig 4. Total pressure distribution of different crosssectional ducts

Table 3. Total pressure drop effects

\begin{tabular}{|c|c|c|c|}
\hline $\begin{array}{c}\text { Duct } \\
\text { Models }\end{array}$ & $\begin{array}{c}\text { Inlet total } \\
\text { pressure } \\
(\mathrm{Pa})\end{array}$ & $\begin{array}{c}\text { Outlet } \\
\text { total } \\
\text { pressure } \\
(\mathrm{Pa})\end{array}$ & $\begin{array}{c}\text { Pressure } \\
\text { drop } \\
(\mathrm{Pa})\end{array}$ \\
\hline Circular & 60.8818 & 27.108 & 33.7738 \\
\hline Square & 57.027084 & 28.41172 & 28.615364 \\
\hline $\begin{array}{c}\text { Rectangular } \\
\text { aspect ratio } \\
2: 1\end{array}$ & 57.731091 & 28.518221 & 29.21287 \\
\hline $\begin{array}{c}\text { Rectangular } \\
\text { aspect ratio } \\
4: 1\end{array}$ & 59.07539 & 27.609636 & 31.465754 \\
\hline Triangular & 56.878998 & 29.970551 & 26.908447 \\
\hline
\end{tabular}

The results of this study have shown that the pressure drop in circular duct is the greatest while triangular duct is the smallest. Similarly, pressure drop increases by increasing aspect ratios of rectangular ducts. Because rectangular ducts at high aspect ratios have higher contact surface areas than duct with smaller aspect ratios.

As shown in Fig.5, the contact area between water and walls in non-circular ducts is less than in circular ones, due to existence of stagnation for some parts of liquid near the sharp corners which reduces water contact with the walls. In turns it decreases pressure drop in non-circular ducts.

Quantitatively, in the circular duct $20.327 \%$, $15.273 \%, 13.5 \%$ and $6.834 \%$ more pressure is lost than triangular, square, rectangular $2: 1$ and rectangular 4:1ducts respectively. Therefore, Circular duct needs the highest pumping power than noncircular ducts to overcome the pressure drop. 


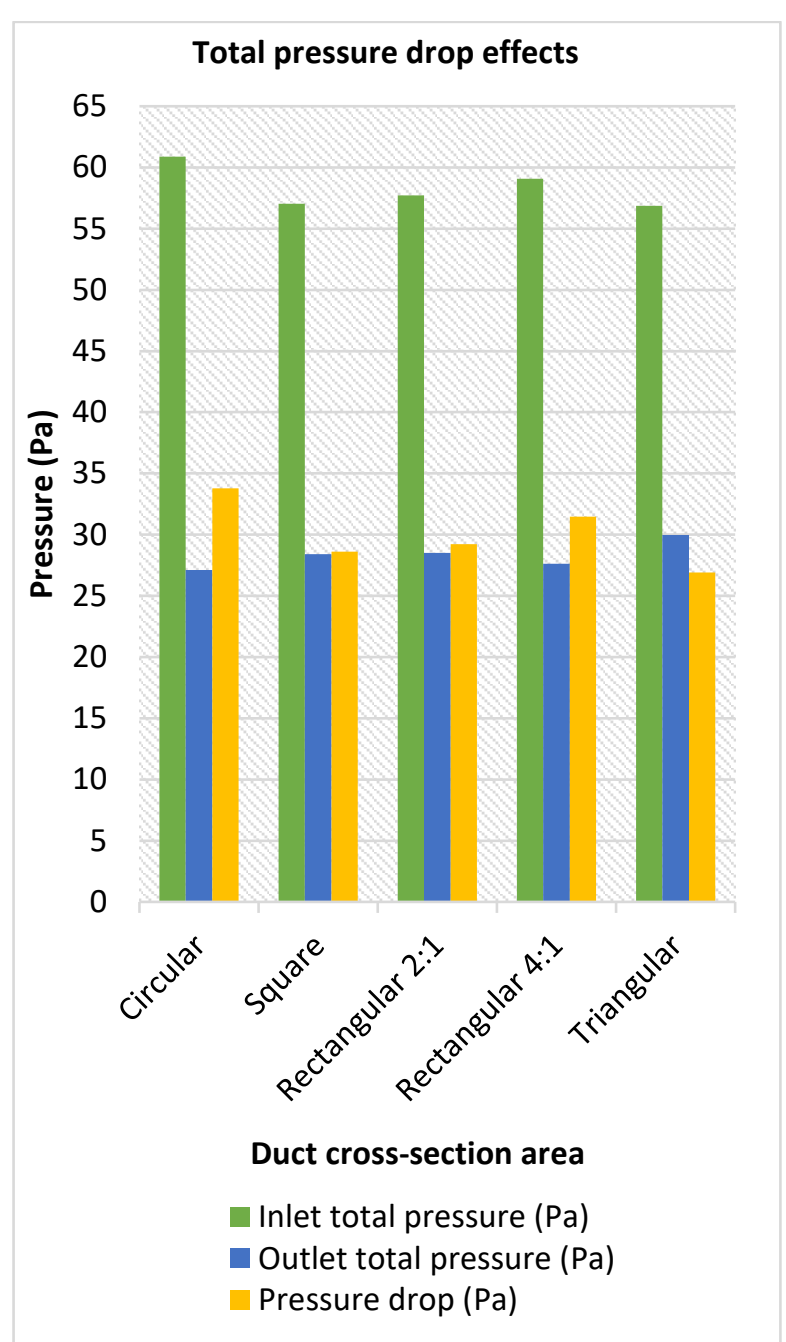

Fig 5. Effect of total pressure drops for different crosssectional ducts

The present work has been compared with the previous work done by Heris et al. [21] at fully developed flow condition, the same hydraulic diameter, operating and boundary conditions. The length of square and triangular cross-sectional ducts was $1 \mathrm{~m}$, and the length of each side was $1 \mathrm{~cm}$ for square and $1.7 \mathrm{~cm}$ for triangular ducts. Finally it is found that the pressure drop increases by changing the duct geometry from triangular to square, and from square to circular ducts. Likewise the pressure drop increases by the increase of the faces of noncircular ducts similar to work done by Heris et al. [21].

\section{CONCLUSIONS}

In this article, pressure drop of water flow in circular, square, rectangular 2:1, rectangular $4: 1$ and equilateral triangle ducts with the same length and hydraulic diameter is studied by using CFD analysis tools.

From the numerical analysis the following conclusions summarize the paper:

- Velocity in the ducts gradually increases from zero at the walls to the maximum at the center;

- At sharper corners there is high amount of friction between water flow and corner walls which causes static section (stagnation) of water in the vicinity of duct corners;

- The pressure drop in circular duct is the greatest while triangular duct is the smallest. In polygonal ducts, pressure drop increases by increasing duct faces;

- Circular duct needs the highest pumping power than non-circular ducts to overcome the pressure drop;

- In rectangular ducts, pressure drop increased with aspect ratios. Because it increases contact surface area in between fluid and walls.

- Therefore, rectangular ducts should be made as nearly square as possible.

Finally, this research work might be used in industries while selecting appropriate duct cross section in evaporators, condensers, economizers and boilers where pressure drop optimization is necessary in duct layout.

\section{REFERENCES}

[1] R.K. Raman, Y. Dewang, J. Raghuwanshi, A Review on Applications of Computational Fluid Dynamics. International Journal of LNCT, 2 (6), 2018: 137143.

[2] R. Teja, F.Z. Pathan, M. Vahadne, Optimization of Heat Transfer through Rectangular Duct. International Research Journal of Engineering and Technology, 2 (4), 2015: 1906-1910.

[3] H.A. Shah, P.T. Patel, K.B. Gaywala, Design and Proportional Computational Assessment between a Conventional and Circular Duct System: An Industrial Air Conditioning-A Case Study. Journal of Emerging Technologies and Innovative Research, 5 (7), 2018: 354-361.

[4] S. Blanka, J. Skočilas, Determination of pressure drop coefficient by CFD simulation. AIP Conference Proceedings, 1608 (1). American Institute of Physics, 2014, 206-210. 
https://doi.org/10.1063/1.4892736

[5] A.R. Al-Obaidi, A. Sharif, Investigation of the three-dimensional structure, pressure drop, and heat transfer characteristics of the thermohydraulic flow in a circular pipe with different twisted-tape geometrical configurations. Journal of Thermal Analysis and Calorimetry, 143, 2021: 3533-3558.

https://doi.org/10.1007/s10973-019-09244-y

[6] P. Kumar, R. Ganesan, A CFD study of turbulent convective heat transfer enhancement in circular pipe flow. International Journal of Civil and Environmental Engineering, 6 (8), 2012: 385-392. http://doi.org/10.5281/zenodo.1333752

[7] Y. Wang, M. Hou, X. Deng, L. Li, C. Huang, H. Huang, G. Zhang, C. Chen, W. Huang, Configuration optimization of regularly spaced short-length twisted tape in a circular tube to enhance turbulent heat transfer using CFD modeling. Applied Thermal Engineering, 31 (6-7), 2011: 1141-1149.

https://doi.org/10.1016/j.applthermaleng.2010. $\underline{12.009}$

[8] A.R. Al-Obaidi, Numerical investigation of flow field behavior and pressure fluctuations within an axial flow pump under transient flow pattern based on CFD analysis method. J Phys Conf Ser. 1279 (1), 2019: 012069.

https://doi.org/10.1088/1742-

6596/1279/1/012069

[9] A.R. Al-Obaidi, Monitoring the performance of centrifugal pump under single-phase and cavitation condition: a CFD analysis of the number of impeller blades. J. Appl. Fluid Mech, 12 (2), 2019: 445-459.

https://doi.org/10.29252/jafm.12.02.29303

[10] S. Ray, D. Misra, Laminar fully developed flow through square and equilateral triangular ducts with rounded corners subjected to $\mathrm{H} 1$ and $\mathrm{H} 2$ boundary conditions. International Journal of Thermal Sciences, 49 (9), 2010: 1763-1775. https://doi.org/10.1016/j.ijthermalsci.2010.03.0 $\underline{12}$

[11] S.Z. Heris, S.H. Noie, E. Talaii, J. Sargolzaei, Numerical investigation of Al2O3/water nanofluid laminar convective heat transfer through triangular ducts. Nanoscale Research Letters, 6, 2011: 179.

https://doi.org/10.1186/1556-276X-6-179
[12] A. Akcayoglu, C. Nazli, A Comprehensive Numerical Study on Thermohydraulic Performance of Fluid Flow in Triangular Ducts with Delta-Winglet Vortex Generators. Heat Transf. Eng., 39 (2), 2018: 107-119.

https://doi.org/10.1080/01457632.2017.128804 $\underline{6}$

[13] S.L. Braga, F.E.M. Saboya, Turbulent Heat Transfer and Pressure Drop in an Internally Finned Equilateral Triangular Duct. Exp. Therm. Fluid Sci., 12 (1), 1996: 57-64.

https://doi.org/10.1016/0894-1777(95)00069-0

[14] C.W. Leung, S.D. Probert, Forced Convective Turbulent-Flows through Horizontal Ducts with Isosceles Triangular Internal Cross Sections. Appl. Energy, 57 (1), 1997: 13-24.

https://doi.org/10.1016/S0306-2619(96)00021-9

[15] C.W. Leung, T.L. Chan, S. Chen, Forced Convection and Friction in Triangular Duct with Uniformly Spaced Square Ribs on Inner Surfaces. Heat and Mass Transfer, 37 (1), 2001: 19-25. https://doi.org/10.1007/s002310000130

[16] Z. Li, Y. Gao, Numerical Study of Turbulent Flow and Heat Transfer in Cross-Corrugated Triangular Ducts with Delta-Shaped Baffles. International Journal of Heat and Mass Transfer, 108, 2017: 658-670.

https://doi.org/10.1016/J.IJHEATMASSTRANSFER .2016 .12 .054

[17] F. B. Gessner, J. B. Jones, A preliminary study of turbulence characteristics of flow along a corner. ASME J. Basic Eng., 83 (4), 1961: 657-661.

https://doi.org/10.1115/1.3662287

[18] M.S. Vazquez, W.V. Rodriguez, R. Issa, Effect of ridged Walls on the heat transfer in a heated square duct. International Journal of Heat and Mass Transfer, 48 (10), 2005: 2050-2063.

https://doi.org/10.1016/i.ijheatmasstransfer.200 $\underline{4.10 .036}$

[19] S. Gavrilakis, Numerical simulation of low Reynolds number turbulent flow through a straight square duct. Journal of Fluid Mechanics, 244, 1992:101-112.

https://doi.org/10.1017/S0022112092002982

[20] F.B. Gessner, J.B. Jones, On some aspects of fully developed turbulent flow in a rectangular channel. Journal of Fluid Mechanics, 23 (4), 1965: 689-713.

https://doi.org/10.1017/S0022112065001635 
[21] S.Z. Heris, F. Oghazian, M. Khademi, E. saeedi, Simulation of Convective Heat Transfer and Pressure Drop in Laminar Flow of Al203/water and $\mathrm{CuO} /$ water Nanofluids through Square and
Triangular Cross-sectional Ducts. Journal of Renewable Energy and Environment, 2 (1), 2015: 6-18.

https://doi.org/10.30501/JREE.2015.70065 